Enduring Extremes:

Polar Vortex, Drought, and Climate Change Beliefs

Benjamin A. Lyons

Department of Politics

University of Exeter

Exeter, UK

Ariel Hasell

Department of Communication Studies

University of Michigan

Ann Arbor, MI, USA

Natalie Jomini Stroud

Department of Communication Studies

University of Texas at Austin

Austin, TX, USA

Contact corresponding author benjamin.a.lyons@gmail.com

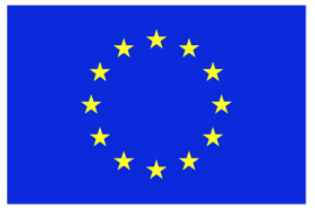

mec 


\title{
Enduring Extremes? \\ Polar Vortex, Drought, and Climate Change Beliefs
}

\begin{abstract}
Some extreme weather events may be more likely to affect climate change beliefs than others, in part because schema individuals possess for different events could vary in encouraging such links. Using a representative sample of U.S. adults and geocoded National Weather Service data, we examine how a range of extreme weather event categories relate to climate change beliefs, and the degree to which individuals' self-reported experiences are shaped by their political views across event types. For tornado, hurricane, and flood events, we find no link with beliefs. For polar vortex and drought events, we find that although self-reported experience is linked with climate beliefs, reporting of these experiences is influenced by political identity and partisan news exposure. These findings underscore a limited role for extreme weather experiences in climate beliefs, and show that events more open to interpretation, such as droughts and polar vortex disturbances, are most likely to be seen through a partisan lens.
\end{abstract}

Keywords: Climate change, extreme weather, personal experience, partisan media 
Low levels of certainty about climate change may stem from the difficulty of experiencing it directly. A developing literature investigates the impact of exposure to anomalous weather patterns on beliefs about climate change. Researchers are interested in these effects because experiential learning can vividly render otherwise abstract risks concrete (Howe et al., 2013). Rather than relying on statistics about climate change, individuals can refer to their lived experience.

A series of studies have linked fluctuations in local temperatures to climate change beliefs (Egan \& Mullin, 2012; Hamilton \& Stampone, 2013; Zaval et al., 2014). By scientific standards, however, local temperature fluctuations are poor evidence of climate change (Egan \& Mullin, 2012; Zaval et al., 2014). Conversely, because climatologists have noted climate change's contribution to events such as hurricanes and droughts (Trenberth, 2012), such events are more acceptable evidence of climate change (Deryugina, 2013). For this reason, extreme weather events may serve as "teachable moments" about climate change (Howe et al., 2013, p. 12). Personally experiencing these events and making sense of them may result in updating beliefs about climate change. In this paper, we focus on five extreme weather events (polar vortex disturbance, ${ }^{1}$ drought, tornado, flood, and hurricane) and evaluate how they relate to climate change beliefs.

We also examine factors that could influence how individuals integrate personal weather experiences with pre-existing schema (Nisbet, 2011) -- including education (Tichenor et al., 1970), partisanship (McCright, Dunlap, \& Xiao, 2014), and partisan media exposure (Feldman et al., 2014). Finally, the effects of different categories of weather events may vary because mental

\footnotetext{
${ }^{1}$ We use the colloquial term "polar vortex" for the extreme cold events stemming from an influx of Arctic air over the continental United States in 2014 and 2015. It should be noted, however, that this usage differs from the definition used by meteorologists and climatologists (Albon, 2014; Fischetti, 2014). In the scientific community, the polar vortex refers to planetary-scale high-latitude circumpolar circulation (see Frauenfeld \& Davis, 2003).
} 
models for some types of weather events may be more connected schematically to mental models of climate change (Weber \& Stern, 2011), and may vary depending on whether we analyze selfreported or objective event exposure.

We find that reported experience with polar vortex and drought events is related to climate beliefs. These associations are often moderated by education and political orientation, but partisan media use rarely affects these experience-belief links. Inclusion of objective indicators or spatial variables shows that these two event categories are also subject to political identity-derived bias in self-reporting. This set of results suggests extreme weather plays a limited role in climate beliefs, and worldviews can alter the subjective experience of certain events. In the following sections, we review the literature on extreme weather and climate attitudes, potential moderators of these experiential effects, and biased reporting of these experiences.

\section{Extreme weather events and climate change attitudes}

Skepticism surrounding climate change remains widespread in the U.S., particularly among conservatives (Egan \& Mullin, 2017). Americans attach a low level of issue salience to climate change (Egan \& Mullin, 2017), including those who embrace the scientific consensus. Combined, conservatives' skepticism and liberals' apathy pose challenges to forming an effective response (Hornsey et al., 2016). Personal experience with the effects of climate change may influence public attitudes, however. Such experiences may reduce the psychological distance that characterizes how many relate to climate change (Spence, Poortinga, \& Pidgeon, 2012). Because of the asymmetry in how liberals and conservatives process information relating to the issue, the benefit of extreme weather events may be to prioritize climate action among liberals, rather than to persuade conservatives (Zhou, 2016). 
A few studies have examined the link between experiencing an extreme weather event and climate change beliefs. For example, Carlton et al. (2016) found attitudinal effects of the 2012 Midwestern U.S. drought, as did Demski et al. (2017) for the 2013-14 U.K. winter floods. Rudman et al. (2013) found that students linked the personal negative impact of Superstorm Sandy, but not Hurricane Irene, to greater implicit preference for a "green" politician.

In a broader approach, Konisky et al. (2016) tested the relationship between exposure to certain types of extreme weather and climate change concern. They found a modest relationship between experience and concern, which was limited to recent events. The study used a measure that pooled a variety of extreme weather forms connected to climate change, including "warmer temperatures, more heat waves and drought, increased precipitation, increased tropical storms, and sea-level rise" (2016, p. 536). This varied measure of extreme weather exposure may not fully capture the ways in which such events may influence public opinion. In particular, some extreme events may affect climate change beliefs differently than others.

Rather than looking at extreme weather as a whole, we propose to look at categories of extreme weather events independently. As Petty and Cacioppo (1986, p. 165) write, "one of the most important variables affecting information processing activity is the extent to which a person has an organized structure of knowledge (schema) concerning an issue." One way that different types of weather events may lead to differential impacts on climate change beliefs, then, is based on the experiencer's existing schema, or underlying belief structure, for each phenomenon. Schema are dynamic and frequently updated based upon new experiences and information (Wadsworth, 1984); typically, new information is accommodated within existing schema rather than resulting in new schema. This can result in poor schematic representations of new events related to climate change because individuals are inclined to connect these observations with 
“existing local pressures for which schemas had been developed" (Kuruppu \& Liverman, 2011, p. 10). In other words, it is not clear whether new events will be schematically connected to other weather events that are not closely tied to climate change, or whether they will be schematically related to climate change. For this reason, some extreme weather schemas may be more compatible with climate change than others (Weber \& Stern, 2011).

Due to lack of research in this domain, we are ultimately agnostic about specific differences across events. For example, when individuals encounter an unfamiliar event, such as a polar vortex disturbance, causal information should be particularly salient. Because novel phenomena like polar vortex disturbances call for explanation among both the media and the public, studies such as Kim et al. (2014), which attributed the destabilized polar jet stream (and attendant extreme cold in the continental U.S.) to warmer oceans and Arctic sea-ice loss, gained traction in media reports (e.g., Holthaus, 2014). The under-construction schema for polar vortex disturbances may place this information centrally, as individuals form a cognitive network around the new concept (Ahn, Brewer, \& Mooney, 1992). This could allow polar vortex experiences to exert greater influence over climate beliefs. However, it is also possible that initial centrality of climate change in the polar vortex mental model could lead to political identityderived bias in perception of the phenomenon (e.g., Howard, 2014; Schlossberg, 2015).

Individuals may have well-developed schemas for other events (Kuruppu \& Liverman, 2011), making them resistant to a new climate change association, but particularly intense cases (e.g., a 100-year flood, or record-breaking hurricane) might lead to a tipping point that produces an attributional shift in the underlying cognitive schema of the event. It is unclear, however, if some types of events more easily reach such a tipping-point stage than others.

\section{Selected Events}


Previous research using geospatial weather data has pooled all manifestations of extremity into one measure (Konisky et al., 2016). Because we are interested in the way in which different events are processed and connected to climate change, we focus on a variety of discrete event types. Our study builds on prior work regarding public perceptions that focused on hurricanes (Rudman et al., 2013), tornadoes (Leiserowitz, 2004), drought (Carlton et al., 2016), and floods (Demski et al., 2017). Both climatologists (Peterson et al., 2012; Trenberth, 2012) and the media (Desmki et al., 2017) have attributed increased likelihood or intensity of these events to climate change, albeit with varied degrees of certainty (Trenberth, 2012). Despite the connections made in the media, however, people learn about each category in contexts without an explicit link to climate change.

Because of our interest in the schema individuals use to contextualize weather experiences, we also examine a novel event: polar vortex disturbances. Relatively new to public consciousness, the term "polar vortex" became a part of lay vocabularies in the U.S. after an extreme cold event in January 2014 received extensive media coverage (Shepherd, 2016; Waugh et al., 2017). The concept of a polar vortex disturbance was used to describe a low-pressure zone surrounding the Polar Region that pushed arctic air into Canada and the U.S. ${ }^{2}$ A similar polar vortex event resulted in record low temperatures in the U.S. in February 2015. Polar vortex was likely a novel concept given the dearth of coverage of the term prior to the 2014 event. By analyzing the possible linkage between climate change and polar vortex, we can assess whether the two were connected in people's minds. ${ }^{3}$

\footnotetext{
${ }^{2}$ We note that because we examine the public's experience with and interpretation of these events, we again refer here to the popular understanding of polar vortex disturbances as covered in media reports, which does not fully align with the term's usage in the scientific community.

${ }^{3}$ It is important to note how the interpretation and effects of polar vortex disturbances may differ from cold snaps in general (e.g., Capstick \& Pidgeon, 2014). While both types of events have similar outcomes on a physical level,
} 
As an overall set, the events we selected range across experiential qualities of extremity (e.g., aridity, cold, precipitation, wind speed) and the likely existing knowledge structures.

\section{Moderators of Experiential Effects}

Several factors can influence how individuals integrate personal weather experiences with their preexisting schema (Nisbet, 2011). Partisanship and ideology structure beliefs about climate and related policy, particularly in the U.S. (e.g., Dunlap, McCright, \& Yarosh, 2016; Hornsey et al., 2016; McCright, Dunlap, \& Xiao, 2014). It is thus not surprising that individuals often see weather through a partisan lens (e.g., Borick \& Rabe, 2017).

Education's role may be more complicated. Educated individuals are often better equipped to find, make sense of, and retain new information (Tichenor et al., 1970). Better educated individuals may be more likely to encounter and contextualize attributional information about extreme weather. Initially, this may seem to contradict Egan and Mullin (2012), who found that those with a high school education or less were strongly influenced by recent temperatures, while those with advanced degrees were essentially unaffected. The authors attribute the result to differences in the tendency to rely on heuristics (Petty \& Cacioppo, 1986), with short-term local temperature changes serving as poor evidence for the educated and as an appealing heuristic for the less-educated. For this same reason, we would expect that the direction of the effect would flip for events that constitute stronger evidence. Extreme weather events arguably meet this requirement, as climate scientists attribute their increasing extremity to anthropogenic climate

polar vortex disturbances may differ from cold snaps in the minds of members of public -- as something new -because the event was treated as such in media coverage (e.g., Holthaus, 2014), which stressed the event's causality. 
change (Otto, 2017; Stott, 2016;), and media reports have begun to convey such information (Captsick \& Pidgeon, 2014). ${ }^{4}$

Finally, research has demonstrated that media use is connected to beliefs about climate change (e.g. Zhao, 2009). During the five years that serve as the focal point of our study, media frequently talked about extreme weather events and climate change. ${ }^{5}$ Partisan media, in particular, can influence beliefs about climate change, with over-time measurement suggesting a causal relationship (Feldman et al., 2014). Because partisan news differs in its presentation of climate change, attending to such media enhances "belief gaps" between liberal Democrats and conservative Republicans in the U.S. (Nisbet et al., 2015; Veenstra et al., 2014). Because partisan news reinforces its audience's attachment to their political identities (Levendusky, 2013), it can influence how evidence is perceived (Jerit \& Barabas, 2012) - potentially even if that evidence is personal experience. Partisan news exposure may result in discounting or amplifying the connection between extreme weather and climate change, depending on its slant.

\section{Biased Reporting}

Evidence of biased recall is fairly common in perceptions of extreme temperatures (e.g., Hamilton et al., 2016a; Howe, 2018; Howe \& Leiserowitz, 2013; McCright et al., 2014; but see

\footnotetext{
${ }^{4}$ It should be further noted that education moderates the effect of party on beliefs, enhancing adherence to group norms. Compared to those with less education, better-educated Democrats are more likely to believe in, and bettereducated Republicans more likely to reject, climate change (Hamilton, 2011).

${ }^{5}$ Using the Factiva database, we searched between June 1, 2010 and May 31, 2015. Of the articles mentioning global warming or climate change in The New York Times, Washington Post, or Wall Street Journal (top circulating newspapers), 384 articles mentioned flood, 81 articles mentioned tornado, 512 mentioned hurricane, 519 mentioned drought, and 21 mentioned polar vortex. Of the programs mentioning global warming or climate change in Fox News programs Hannity, Special Report with Brett Baier, and Your World with Neil Cavuto (the conservative sources available in the database for the period of analysis), 81 mentioned flood, 46 tornado, 95 hurricane, 40 drought, and 1 polar vortex. Of the programs mentioning global warming or climate change in MSNBC programs Hard Ball, The Rachel Maddow Show, and The Last Word with Lawrence O'Donnell (the liberal sources available in the database for the period of analysis, note Last Word started 9/27/10), 32 mentioned flood, 12 tornado, 56 hurricane, 17 drought, and 0 polar vortex. These results show that those attentive to the media would have heard connections between these extreme events and climate change, albeit with different focuses and intensities across the events and media outlets.
} 
Ripberger et al., 2017). Less work has examined biased recall for the more specific extreme events that we examine here. A few recent studies show political identity influence on extreme event reporting, particularly when survey respondents are asked to identify trends (Hamilton et al., 2016b; Shao \& Goidel, 2016). Although precipitation and flooding have increased in recent decades in New Hampshire, for example, only 35\% of the state's residents believe these have increased, with a 26-point gap between liberals and conservatives (Hamilton et al., 2016b).

Although not examining the influence of political identity, Howe et al. (2014) analyze reporting accuracy for those experiencing hurricane, tornado, and drought. The authors find that the public accurately recalls discrete, fast-onset events like tornadoes and hurricanes well, but struggles to perceive drought. Drought events are slow-onset with long time horizons, extend over broad geographical areas, and are defined differently by experts. For these reasons, we might expect droughts and other events more open to interpretation to be more subject to biased reporting driven by political worldviews or partisan media exposure.

\section{Hypotheses}

Because extreme weather events provide experiential evidence, we hypothesize:

H1. Extreme weather experiences will increase the odds of holding climate change beliefs in line with the scientific community's.

We expect that this relationship will be moderated by individuals' characteristics. Educated individuals have a greater ability to extract information from media coverage and contextualize new experiences within more sophisticated schema. Additionally, these events should be especially likely to affect those predisposed to make the link, namely those with a liberal / Democratic political orientation: 
H2. Relationships between extreme weather and climate change beliefs will be stronger among those with a) higher education and b) more liberal / Democratic political orientation.

Similarly, we expect that partisan media consumption conditions the association between personal experience and beliefs, such that:

H3. Relationships between extreme weather and climate change beliefs will be stronger among those exposed to liberal news media, and weaker among those exposed to conservative news media.

We also expect that each extreme weather experience will be processed differently depending on individuals' existing schemas. However, because existing research in this area is nonexistent, we pose a research question:

RQ1. How, if at all, do these relationships vary across weather event categories?

Finally, we analyze whether climate change beliefs are predicted by objective or selfreported experiences of weather events.

RQ2. How, if at all, do self-reported and objective indicators differ in their association with climate beliefs?

We then examine what predicts self-reported experiences, controlling for objective experiences, proposing that more ambiguous (drought) and more novel (polar vortex) weather events will be more subject to biased reporting driven by political orientations and media diets.

H4. For drought and polar vortex, political orientation and partisan news media exposure will predict reported experience above and beyond objective or spatial measures.

\section{Methods}

\section{Data}


This study employs previously unpublished survey data from the Pew American Trends Panel (ATP), a national, probability-based online panel of adults in the United States. Adults who use the internet participated in the panel via self-administered Web surveys, and adults who do not use the internet participated via computer-assisted telephone interviewing or mail. Data employed in this study come from the ATP's wave 11, fielded from June 2 to June 29, 2015. By wave $11,77.1 \%$ of the 5,338 panelists were still active. In total, 3,057 ATP members completed the survey. Taking into account the response rate to the probability-based recruitment survey and percent of those respondents who agreed to participate in the panel, the cumulative response rate for wave 11 was $3.3 \%$.

Data for objective weather experience comes from the Storm Events Database compiled by NOAA's National Weather Service (NWS). The data include droughts, floods, tornadoes, and hurricanes as measured by each events' Federal Information Processing Standards (FIPS) county location code from 2010-2015. The NWS records were matched to the FIPS county codes for the ATP survey respondents. ${ }^{6}$

\section{Measures}

Climate change beliefs. Three global warming beliefs served as outcome variables. Warming belief was measured dichotomously; 59.2\% of respondents agreed that "there is solid evidence that the average temperature on earth has been getting warmer over the past few decades." Of respondents who agreed with this statement, $74.2 \%$ agreed that the Earth was

\footnotetext{
${ }^{6}$ For objective drought and tornado experience, we matched respondent FIPS with any FIPS having experienced a drought or tornado between 2010-2015, according to NWS. For flood experience, we included any FIPS experiencing flood, flash flood, coastal flood, or lakeshore flood between 2010-2015, according to NWS. For hurricane experience, we matched respondent FIPS with any FIPS having experienced a hurricane between 20102015, according to NWS; we also included any FIPS that experienced extreme weather directly associated with Hurricanes Sandy, Arthur, Isaac, or Irene according to the description of the event by NWS. These included events such as tropical storms, storm surges, and high wind, among others.
} 
warming mostly due to "human activity such as burning fossil fuels," providing an anthropogenic belief measure. Finally, $67.3 \%$ of respondents indicated that the statement "most scientists believe that global warming is occurring," was more accurate than "most scientists believe that global warming is not occurring" or "most scientists are unsure about whether global warming is occurring or not," providing a scientific consensus belief measure. Each belief is considered in keeping with consensus among the scientific community (IPCC, 2014).

Extreme weather experiences. Self-reported extreme weather experiences were measured dichotomously, asking whether respondents had experienced each severe event in the past five years: $21.7 \%$ of respondents reported a polar vortex experience, $41.0 \%$ a drought, $19.8 \%$ a tornado, $29.3 \%$ flood, and $16.7 \%$ a hurricane.

Based on NWS objective measures, $21.3 \%$ lived in a county where a flood was recorded over the time period, $25.3 \%$ a tornado, $4.3 \%$ a hurricane, and $4.4 \%$ drought. We take a different approach with the polar vortex disturbances due to their widespread nature (affecting air temperatures in 42 states in 2014, for example [AccuWeather, 2014]), and the lack of NWS records of their effects. We instead look at the effects of self-reported experience using U.S. Census regions to examine spatial variation.

Moderators. Education, political orientations, and media exposure were examined as moderators. Respondents had a median education of a Bachelor's degree. $27.5 \%$ reported being very liberal or liberal, $38.7 \%$ moderate, and $33.8 \%$ conservative or very conservative. $50.8 \%$ affiliated with or leaned Democrat, $41.7 \%$ affiliated with or leaned Republican, and 7.5\% leaned toward neither.

We employ partisanship as our focal political orientation for interaction terms (e.g., Zhou, 2016) in part due to widespread "ideological innocence" (Kinder \& Kalmoe, 2017). That 
said, we also examine ideology, along with a combined party-ideology measure ${ }^{7}$ (e.g., Dunlap et al., 2016; Kahan, 2015; Ripberger et al., 2017; Feldman \& Hart, 2018), in supplementary analyses. For parsimony, we report the results using partisanship, and footnote any significant disparities from the alternate specifications.

Media exposure was measured with additive scales. Respondents were provided an inventory of sources and asked to indicate which they "got news from in the past week." Liberal news consisted of: Huffington Post, Real Time with Bill Maher, MSNBC, Daily Show, and Last Week Tonight with John Oliver $(\mathrm{M}=.64, \mathrm{SD}=.93)$. Conservative news consisted of: Fox News (cable channel), Drudge Report, Breitbart, Rush Limbaugh Show (radio), and Sean Hannity Show (radio) $(\mathrm{M}=.59, \mathrm{SD}=.78)$. These scales were also standardized to z-scores.

Controls. Each analysis also controlled for age $(\mathrm{M}=52.69, \mathrm{SD}=17.05)$, gender $(51.7 \%$ female), and race (79.0\% white, $7.4 \%$ black, $7.0 \%$ Hispanic). In robustness checks, we also include Census region as a spatial control variable.

\section{Analytical Framework}

To test our hypotheses and research question, we fitted binary logistic regression models for our three dichotomous climate change belief variables. Our models first included self-reports for each extreme weather event type. Next, we predicted climate beliefs by objective indicators, and then added the self-reports and objective indicators concurrently. Finally, we addressed reporting bias with follow up analyses predicting self-report by political variables while accounting for objective indicators or spatial variables.

\footnotetext{
${ }^{7}$ Partisanship and ideology are similarly correlated with our dependent variables. Party and ideology, respectively, correlate with belief that Earth is warming $(\mathrm{r}=-.46, \mathrm{p}<.001 ; \mathrm{r}=-.47 \mathrm{p}<.001)$, that humans are the cause $(\mathrm{r}=-.32$, $\mathrm{p}<.001 ; \mathrm{r}=-.34, \mathrm{p}<.001)$ and that scientists agree $(\mathrm{r}=-.39, \mathrm{p}<.001 ; \mathrm{r}=-.40, \mathrm{p}<.001)$. Thus, we averaged these 5-pt. ideology and party responses $(r=.61 ; \mathrm{M}=2.94, \mathrm{SD}=1.20)$ and standardized to a $\mathrm{z}$-score to facilitate interpretation (Kahan et al., 2017).
} 


\section{Results}

\section{Self-Reports}

The first logistic regression modeled the belief that climate change is occurring (Table 1, Column 1). Self-reported polar vortex $(\operatorname{Exp}(B)=1.37, p<.01)$ and drought experiences $(\operatorname{Exp}(B)$ $=1.48, p<.001)$ were significantly associated with the belief that Earth is warming. The other extreme weather experiences were not significant predictors. The next analysis modeled anthropogenic belief (Table 1, Column 2). Polar vortex experience $(\operatorname{Exp}(B)=1.56, p<.01)$ and drought experience $(\operatorname{Exp}(B)=1.28, p<.05)$ were significantly associated with anthropogenic belief; the other extreme weather experience variables were not. The third model looked at scientific consensus belief (Table 1, Column 3). Again, polar vortex $(\operatorname{Exp}(B)=1.44, p<.01)$ and drought experiences $(\operatorname{Exp}(B)=1.22, p<.05)$ were significantly associated with belief in scientific consensus.

\section{Table 1}

These tests showed consistent relationships between self-reported experiences of polar vortex or drought and climate change beliefs in line with the scientific community's. We focus on these in our subsequent analyses. The next models examined the potential for heterogeneous effects of these two types of extreme weather (Table 2). ${ }^{89}$

\footnotetext{
${ }^{8}$ When substituting either ideology or a party-ideology averaged term in the place of party, there are a few instances of shifting effect sizes. While party and ideology interact with self-reported drought experience to predict belief that the Earth is warming, $(\operatorname{party} \operatorname{Exp}(B)=.89, p<.05$; ideology $\operatorname{Exp}(B)=.77 \mathrm{p}<.05)$, the average term's interaction was only marginally significant at $\operatorname{Exp}(\mathrm{B})=.81, \mathrm{p}=.055$. Swapping ideology in place of party also produces a significant interaction with polar vortex experience in predicting belief that humans are causing climate change, $\operatorname{Exp}(B)=.59, \mathrm{p}<.01$. In general, these differences support our takeaway that partisanship and ideology moderate associations between self-reported drought/polar vortex experience and climate beliefs.

${ }^{9}$ We conducted a series of supplementary analyses. First, we tested a 4-point ordinal dependent variable for climate change belief that combined our warming and anthropogenic belief measures. We also modeled potential interactions for those weather event categories that did not produce main effects - hurricane, drought, and flood with education, party/ideology, and liberal/conservative media. These interactions were not significant. See Appendix Tables A1-A2.
} 
Table 2

The relationships between polar vortex experience and warming $(\operatorname{Exp}(\mathrm{B})=1.21, p<.01)$ and consensus $(\operatorname{Exp}(B)=1.19, p<.05)$ beliefs strengthened as education increased. Polar vortex experience's association with warming belief was also stronger among Democrats than Republicans $(\operatorname{Exp}(B)=.85, p<.05)$. Drought experience's association with warming belief $(\operatorname{Exp}(\mathrm{B})=.85, p<.05)$ was stronger among Democrats than Republicans.

To address H3, measures of liberal and conservative-leaning news use were added to each model, along with their interactions with polar vortex and drought experience (Appendix Table A3). We find one significant interaction: Conservative news use was associated with a weaker link between polar vortex experience and belief that the Earth is warming $(\operatorname{Ex}(B)=.68, p$ $<.01){ }^{10}$

\section{Objective Indicators}

We replicate these analyses with objective indicators of hurricane, tornado, flood, and drought. We do not include an objective indicator of polar vortex disturbance, as the technical geographic distribution of these atmospheric disturbances is too large to be discriminant. We find that none of these objective indicators of extreme weather events are associated with climate beliefs (Table 3). We also split the objective indicators between recent (2014-15) and more distant events (2010-2013), as shown in Appendix Table A4, showing one difference: Respondents living in an area exposed to a hurricane in the more recent time period were more likely to believe the Earth is warming $(\operatorname{Exp}(B)=2.08, p<.05)$.

Table 3

\footnotetext{
${ }^{10}$ We also include spatial controls (US Census Regions) as a robustness check for our self-reported experience models, with no substantive difference in results.
} 
Next, we include self-report and objective indicators simultaneously (Table 4). These models show that the relationships between self-reported drought experience and climate beliefs persist with the inclusion of the objective drought indicator, suggesting biased reporting.

Following this finding, we address potential sources of differential reporting for drought and polar vortex. $^{11}$

Table 4

\section{Biased Recall}

Polar Vortex. Because of the geographically dispersed, atmospheric nature of polar vortex disturbances, we look at identity-driven differential experience reporting while accounting for U.S. Census region. ${ }^{12}$ First, we modeled reported polar vortex experience with U.S. Census regions as controls and the West held out as the reference category. This model showed Republicans were less likely to report polar vortex experience, $\operatorname{Exp}(B)=.91, p<.01$, while those exposed to liberal media were more likely, $\operatorname{Exp}(B)=1.15, \mathrm{p}<.01$, controlling for region of residence (full results in Appendix, Table A5).

We then looked at bias within regions, as the severity of the events and related media coverage varied widely (Albon, 2014; Hamik et al., 2016; Lipman, 2015; Overland et al., 2015; Wolter et al., 2015). To do so, we examined predictors of reporting among respondents in the Northeast, Midwest, South, and West separately, using logistic regression for each. Results

\footnotetext{
${ }^{11}$ Although there was no difference in how self-reported and objective measures of flood, hurricane, or tornado experience related to climate change, we ran additional tests predicting self-reports while controlling for objective indicators. We find two potential sources of political bias, with liberal media use predicting flood self-report above and beyond our objective measure, $\operatorname{Exp}(B)=1.13, \mathrm{p}<01$, and party predicting hurricane self-report above our objective measure, $\operatorname{Exp}(B)=.92, p<.05$.

12 We again performed robustness tests for our party/ideology measure in our models of biased reporting. There was no effect in the model predicting drought self-report. In the four regional polar vortex models, there was one distinction in using the combined measure in the place of party: In the Midwest model, party was only marginally significant, $\operatorname{Exp}(B)=.89, p=.053$ vs. $\operatorname{Exp}(B)=.79, p=.022$ when using the combined measure.
} 
(shown in Table 5) show significant effects of political variables on reporting, particularly in regions where the effects of polar vortex disturbances may have been more open to interpretation.

In the South and Midwest, Republicans were significantly less likely to report the experience $(\operatorname{Exp}(B)=.82, p<.01 ; \operatorname{Exp}(B)=.89, p=.053)$. In the Midwest and West, liberal media exposure increased the likelihood of reporting $(\operatorname{Exp}(B)=1.25, p<.05 ; \operatorname{Exp}(B)=1.42, p<$ $.05)$. In the Northeast, which bore the worst of the 2014-15 polar vortex disturbances and received a great deal of the related media coverage, none of the political variables predicted experience reporting in the final model.

Table 5

Drought. Finally, we address bias in drought reporting as seen in Table 6. An initial model shows that self-reported experience is predicted by the objective indicator, ${ }^{13}$ as well as liberal news exposure $(\operatorname{Exp}(B)=1.24, \mathrm{p}<.01)$. Liberal news exposure does not moderate the link between objective and subjective experience, however, as seen in column 2.

Table 6

\section{Discussion}

In this study, we combine nationally representative survey data and NWS storm event data disaggregated by event category to explore how the public perceives and makes sense of various extreme weather events in relation to climate change. We find that self-reported experience with drought and polar vortex disturbances are associated with climate beliefs more in line with the scientific community's, and these relationships are often intensified by education and political worldviews. However, the addition of objective weather indicators in the case of

\footnotetext{
${ }^{13}$ Splitting the objective indicator by recent/distant drought events shows that both independently predict selfreport.
} 
drought, and analysis of reporting propensity with spatial controls in the case of polar vortex suggest both experiences are shaped by politics.

Those exposed to liberal media are more likely to report drought experience, and our objective indicator of drought is not associated with climate beliefs. Similarly, liberal media exposure increases the odds of reporting polar vortex experience in the American West and Midwest, while partisanship and ideology predict reporting in the South and Midwest. Political variables played little role in reporting for those hit hardest by the media-event polar vortex disturbances of 2014 and 2015 in the Northeast. These findings suggest tempering optimism about extreme weather as teachable moments (Howe et al., 2013). In broad terms, the limited long-term effects of extreme weather events shown here support Konisky et al. (2016), who found any effects to be short lived; our results show limited effects across event categories. As Hornsey et al. (2016, p. 622) sum up, “many intuitively appealing variables (such as [...] experience of extreme weather events) [are] overshadowed in predictive power by values, ideologies, worldviews and political orientation."

Although events do not appear to lead to differential influence on climate beliefs as hypothesized, the schema of certain events may instead cause existing climate beliefs and the political identities from which they stem to inform subjective experience. Perhaps because drought and polar vortex are less discrete experiences, and may be easily linked with climate change, we see political bias in reporting. Science communicators explicitly connected polar vortex events with climate change (Borenstein, 2014; Walsh, 2014), and such events are associated with polar regions, which are prominent in climate change discourse (Hamilton, 2008; Hamilton \& Lemcke-Stampone, 2014), and so may fit a widely held mental model of climate change. Drought may fit more clearly with conceptions of global warming (Borick \& Rabe, 
2017). In both cases, the ease of the connection may have promoted the salience of the experience for those predisposed to be concerned the Earth's changing climate.

Although we suspected that media use would in part determine how individuals processed weather experiences, we did not fully anticipate how. Media use rarely moderated experience's link to climate beliefs, but it did bias whether individuals reported ambiguous event experiences at all. Event attribution is a relatively new domain of climate science (Otto, 2017; Stott, 2016), and until recently climatologists have been wary of causally tying discrete events to climate change (Capstick \& Pidgeon, 2014; Trenberth, 2012). As such, these links may only be beginning to saturate news coverage (Diffenbaugh, 2017), particularly as scientists are able to make such attributions more quickly (Duhaime-Ross, 2018). For example, though we found little evidence that hurricane experiences affect climate beliefs, we did find a modest effect of more recent hurricanes in our time split model. This may suggest that communicative efforts to connect extreme weather events to climate change are becoming more effective. While we cannot test this possibility here, it would be a worthwhile endeavor for future research.

Climate change presents a unique set of communicative challenges, and our study adds to these concerns. We show that perceived, rather than objective, measures of some extreme weather events correlate with climate change beliefs. The link was particularly evident among those with more education and those holding more liberal/Democratic beliefs. Strategic use of extreme weather to discuss climate change thus has three distinct challenges: It must help people to recognize their experience of these events, to overcome their partisan tendencies to contextualize them, and to inform those with less education about links to climate change. Another challenge is that climate change tends to not be a highly prioritized political issue, even among those who are very concerned about climate change. As we find evidence that experience 
of less discrete extreme events are processed through partisan lenses, science communicators need to consider how connecting these events to climate change will affect both concern and political issue prioritization by the public. It might be that public prioritization of climate change mitigation would be dependent on specific extreme weather events, and not all events will benefit from emphasis on the direct connection to climate change.

Although this study provides a comprehensive look at different weather events using a national probability sample and objective weather indicators, it is important to note that the cross-sectional nature of the data prohibits us from drawing causal conclusions (although proposed relationships have been in evidence in research using longitudinal data e.g., Konisky et al., 2016). ${ }^{14}$ Several measurement issues in this study are also worth noting. The survey did not define polar vortex for respondents, or explain that the definition of drought varies even among experts. ${ }^{15}$ Future research should evaluate the public's understanding of these terms, and whether defining these terms changes the relationships documented here.

We also asked about the experience of extreme weather events over the past five years; whether the results would differ over different time frames is unclear. Our analysis of more recent objective experiences offers some suggestion that this is an important consideration (It should also be noted that polar vortex disturbances became national news only in the later period

\footnotetext{
${ }^{14}$ Panel data would be especially useful to shed additional light on polar vortex disturbances, for which due to a lack of an objective indicator we cannot rule out some causal effect in spite of politically motivated reporting.

${ }^{15}$ Because differing forms of drought - meteorological, agricultural, hydrological, and social-economic -begin and end at different times, any measure of drought is unlikely to align perfectly with public understanding. Only severe droughts are included as extreme events in the NWS database (events rated at D2 - D4 on the Drought Monitor scale east of the Rocky Mountains, and those rated at D3- D4 west of the Rockies). Therefore, it is possible that the liberal news exposure bias in drought reporting may mean these respondents are more sensitive to the weakest classification of droughts. In other words, because drought is difficult to recognize and takes time, the time to recognition may be moderated by news consumption. However, the long time-horizon of our analysis helps account for this possibility.
} 
of the time frame under study, 2014-15). Similarly, we take a big-picture look at event category effects rather than those of specific events. However, particularly intense, singular exemplar events might be most capable of influencing attitudes (Rudman et al., 2013). Further, the objective measures were matched to the location data available for survey respondents, but we did not have insight into whether respondents moved or spent vacations in affected regions, for example. This slippage could have obscured our ability to find significant effects for the objective measures.

Finally, how extreme weather experiences are connected to climate change beliefs may vary by other factors outside the scope of this study, such as class, gender, and race (e.g., Cutler 2015; Cutler, 2016). Socio-economic factors have systemic influences on attitudes towards science, environmental hazards, and perceptions of risk (Finucane et al., 2000). Future research should further explore how extreme weather affects minority groups or susceptible populations differently, and how they perceive the connection to climate change.

\section{Conclusion}

Our analyses suggest that extreme weather events have little long-term impact on climate beliefs, and political views may shape the salience of more ambiguous weather phenomena. If some extreme weather events do offer a window of change, it may depend on the nature of the preexisting frames surrounding the class of event, and these focusing events may be better suited to increasing salience among liberals than to converting conservatives. 


\section{References}

AccuWeather. (2014, November 11). Only eight states to dodge icy air from slipping polar vortex. Retrieved from https://www.accuweather.com/en/weather-news/polar-vortex-42states/37049255

Ahn, W. K., Brewer, W. F., \& Mooney, R. J. (1992). Schema acquisition from a single example. Journal of Experimental Psychology: Learning, Memory, and Cognition, 18(2), 391.

Albon, M. (2014, April 2). When the media met the polar vortex. Yale Climate Connections. Retrieved from https:/www.yaleclimateconnections.org/2014/04/lost-in-the-snow-whenthe-media-met-the-polar-vortex/

Borenstein, S. (2014, Sept 2) Study links polar vortex chills to melting sea ice. Associated Press. Retrieved from http://bigstory.ap.org/article/study-links-polar-vortex-chills-melting-seaice. Accessed 2 March 2017.

Borick, C., \& Rabe, B. (2017). Personal Experience, Extreme Weather Events, and Perceptions of Climate Change. Oxford Research Encyclopedia of Climate Science. Retrieved 27 Nov. 2017, from http://climatescience.oxfordre.com/view/10.1093/acrefore/9780190228620.001.0001/acre fore-9780190228620-e-311.

Capstick, S. B., \& Pidgeon, N. F. (2014). Public perception of cold weather events as evidence for and against climate change. Climatic Change, 122(4), 695-708.

Carlton, J. S., Mase, A. S., Knutson, C. L., Lemos, M. C., Haigh, T., Todey, D. P., \& Prokopy, L. S. (2016). The effects of extreme drought on climate change beliefs, risk perceptions, and adaptation attitudes. Climatic Change, 135(2), 211-226. 
Cutler, M. J. (2015). Seeing and believing: the emergent nature of extreme weather perceptions. Environmental Sociology, 1(4), 293-303.

Cutler, M. J. (2016). Class, ideology, and severe weather: how the interaction of social and physical factors shape climate change threat perceptions among coastal US residents. Environmental Sociology, 2(3), 275-285.

Demski, C., Capstick, S., Pidgeon, N., Sposato, R. G., \& Spence, A. (2017). Experience of extreme weather affects climate change mitigation and adaptation responses. Climatic Change, 140(2), 149-164.

Deryugina, T. (2013). How do people update? The effects of local weather fluctuations on beliefs about global warming. Climatic Change, 118(2), 397-416.

Diffenbaugh, N. S. (2017, Dec. 29). How we know it was climate change. The New York Times. Retrieved December 30, 2017, from https://www.nytimes.com/2017/12/29/opinion/sunday/climate-change-globalwarming.html?action=click\&pgtype=Homepage $\&$ clickSource=storyheading\&module=opinion-c-col-right-region ${ }^{\circledR}$ ion $=$ opinion-c-col-rightregion $\&$ WT.nav=opinion-c-col-right-region

Duhaime-Ross, A. (2018, Jan. 04). Scientists can now quickly link extreme weather events to climate change. Vice News. Retrieved January 10, 2018, from https://news.vice.com/en_us/article/wjpgdm/scientists-can-now-quickly-link-extremeweather-events-to-climate-change

Dunlap, R. E., McCright, A. M., \& Yarosh, J. H. (2016). The political divide on climate change: Partisan polarization widens in the US. Environment: Science and Policy for Sustainable Development, 58(5), 4-23. 
Egan, P. J., \& Mullin, M. (2012). Turning personal experience into political attitudes: The effect of local weather on Americans' perceptions about global warming. The Journal of Politics, 74(3), 796-809.

Egan, P. J., \& Mullin, M. (2017). Climate Change: US Public Opinion. Annual Review of Political Science, 20, 209-227.

Feldman, L., \& Hart, P. (2018). Broadening exposure to climate change news? How framing and political orientation interact to influence selective exposure. Journal of Communication. Online First.

Feldman, L., Myers, T. A., Hmielowski, J. D., \& Leiserowitz, A. (2014). The mutual reinforcement of media selectivity and effects: Testing the reinforcing spirals framework in the context of global warming. Journal of Communication, 590-611. doi: 10.1111/jcom. 12108

Finucane, M. L., Slovic, P., Mertz, C. K., Flynn, J., \& Satterfield, T. A. (2000). Gender, race, and perceived risk: The'white male'effect. Health, risk \& society, 2(2), 159-172.

Fischetti, M. (2014, July 14). Critics slam reports of a "Polar Vortex" in July. Scientific American. Retrieved from https://blogs.scientificamerican.com/observations/critics-slamreports-of-a-polar-vortex-in-july/

Frauenfeld, O. W., \& Davis, R. E. (2003). Northern Hemisphere circumpolar vortex trends and climate change implications. Journal of Geophysical Research: Atmospheres, 108(D14).

Hamilton, L. C. (2008). Who cares about polar regions? Results from a survey of US public opinion. Arctic, Antarctic, and Alpine Research, 40(4), 671-678.

Hamilton, L. C. (2011). Education, politics and opinions about climate change evidence for interaction effects. Climatic Change, 104(2), 231-242. 
Hamilton, L. C., \& Lemcke-Stampone, M. (2014). Arctic warming and your weather: public belief in the connection. International Journal of Climatology, 34(5), 1723-1728.

Hamilton, L. C., \& Stampone, M. D. (2013). Blowin’ in the wind: Short-term weather and belief in anthropogenic climate change. Weather, Climate, and Society, 5(2), 112-119.

Hamilton, L. C., Hartter, J., Keim, B. D., Boag, A. E., Palace, M. W., Stevens, F. R., \& Ducey, M. J. (2016). Wildfire, climate, and perceptions in Northeast Oregon. Regional environmental change, 16(6), 1819-1832.

Hamilton, L. C., Wake, C. P., Hartter, J., Safford, T. G., \& Puchlopek, A. J. (2016). Flood realities, perceptions and the depth of divisions on climate. Sociology, 50(5), 913-933.

Harnik, N., Messori, G., Caballero, R., \& Feldstein, S. B. (2016). The circumglobal North American wave pattern and its relation to cold events in eastern North America. Geophysical Research Letters, 43(20).

Holthaus, E. (2014, Sept. 03). New study links polar vortex to climate change. Slate. Retrieved December 30, 2017, from http://www.slate.com/blogs/future_tense/2014/09/03/new_study_links_polar_vortex_to_c limate_change.html

Hornsey, M. J., Harris, E. A., Bain, P. G., \& Fielding, K. S. (2016). Meta-analyses of the determinants and outcomes of belief in climate change. Nature Climate Change, 6(6), $622-626$.

Howard, B. (2014, January 09). U.S. cold snap inspires climate change denial, while scientists see little room for doubt. National Geographic. Retrieved from https://news.nationalgeographic.com/news/2014/01/140108-cold-weather-polar-vortexglobal-warming-climate-science/ 
Howe, P. D. (2018). Perceptions of seasonal weather are linked to beliefs about global climate change: evidence from Norway. Climatic Change, 1-14.

Howe, P. D., \& Leiserowitz, A. (2013). Who remembers a hot summer or a cold winter? The asymmetric effect of beliefs about global warming on perceptions of local climate conditions in the US. Global Environmental Change, 23(6), 1488-1500.

Howe, P. D., Boudet, H., Leiserowitz, A., \& Maibach, E. W. (2014). Mapping the shadow of experience of extreme weather events. Climatic Change, 127(2), 381-389.

Howe, P. D., Markowitz, E. M., Lee, T. M., Ko, C. Y., \& Leiserowitz, A. (2013). Global perceptions of local temperature change. Nature Climate Change, 3(4), 352-356.

IPCC (2014). Fifth Assessment Report. Cambridge University Press, Cambridge.

Jerit, J., \& Barabas, J. (2012). Partisan perceptual bias and the information environment. The Journal of Politics, 74(03), 672-684. doi: 10.1017/S0022381612000187

Kahan, D. M. (2015). Climate-science communication and the measurement problem. Political Psychology, 36(S1), 1-43.

Kahan, D. M., Peters, E., Dawson, E. C., \& Slovic, P. (2017). Motivated numeracy and enlightened self-government. Behavioural Public Policy, 1(1), 54-86.

Kim, B. M., Son, S. W., Min, S. K., Jeong, J. H., Kim, S. J., Zhang, X., ... \& Yoon, J. H. (2014). Weakening of the stratospheric polar vortex by Arctic sea-ice loss. Nature Communications, 5, 4646.

Kinder, D. R., \& Kalmoe, N. P. (2017). Neither liberal nor conservative: Ideological innocence in the American public. University of Chicago Press. 
Konisky, D. M., Hughes, L., \& Kaylor, C. H. (2016). Extreme weather events and climate change concern. Climatic Change, 134(4), 533-547.

Leiserowitz, A. A. (2004). Day after tomorrow: study of climate change risk perception. Environment: Science and Policy for Sustainable Development, 46(9), 22-39.

Levendusky, M. (2013). Partisan media exposure and attitudes toward the opposition. Political Communication, 30(4), 565-581. doi: 10.1080/10584609.2012.737435

Lipman, D. (2015). Boston's 2015 snow blitz: How did it compare?. Weatherwise, 68(5), 30-36 McCright, A. M.,, Dunlap, R. E., \& Xiao, C. (2014). The impacts of temperature anomalies and political orientation on perceived winter warming. Nature Climate Change, 4, 1077-1081.

Nisbet, E. C., Cooper, K. E., \& Ellithorpe, M. (2015). Ignorance or bias? Evaluating the ideological and informational drivers of communication gaps about climate change. Public Understanding of Science, 24(3), 285-301.

Nisbet, M.C. (2011). Public opinion and participation. In J.S. Dryzek, R.B. Norgaard, \& D. Schlossberg (Eds.), The Oxford Handbook of Climate Change and Society (pp. 355-368). Oxford University Press, Oxford.

NWS (2007). Storm data preparation. National Weather Service Instruction 10-1605; Department of Commerce, National Oceanic \& Atmospheric Administration. National Weather Service (NWS), Silver Spring.

Otto, F. (2017). Attribution of weather and climate events. Annual Review of Environment and Resources, 42(1).

Overland, J., Francis, J. A., Hall, R., Hanna, E., Kim, S. J., \& Vihma, T. (2015). The melting Arctic and midlatitude weather patterns: Are they connected?. Journal of Climate, 28(20), 7917-7932. 
Peterson, T. C., Stott, P. A., \& Herring, S. (2012). Explaining extreme events of 2011 from a climate perspective. Bulletin of the American Meteorological Society, 93(7), 1041-1067.

Petty, R. E., \& Cacioppo, J. T. (1986). Message elaboration versus peripheral cues. In Communication and Persuasion (pp. 141-172). Springer, New York, NY.

Ripberger, J. T., Jenkins-Smith, H. C., Silva, C. L., Carlson, D. E., Gupta, K., Carlson, N., \& Dunlap, R. E. (2017). Bayesian versus politically motivated reasoning in human perception of climate anomalies. Environmental Research Letters, 12(11), 114004.

Rudman, L. A., McLean, M. C., \& Bunzl, M. (2013). When truth is personally inconvenient, attitudes change: the impact of extreme weather on implicit support for green politicians and explicit climate-change beliefs. Psychological Science, 24(11), 2290-2296.

Schlossberg, T. (2016, December 15). Feeling a chill? Blame the polar vortex. And global warming. New York Times. Retrieved from https://www.nytimes.com/2016/12/15/science/feeling-a-chill-blame-the-polar-vortex-andglobal-warming.html

Shepherd, T. G. (2016). Effects of a warming Arctic. Science, 353(6303), 989-990.

Shao, W., \& Goidel, K. (2016). Seeing is believing? An examination of perceptions of local weather conditions and climate change among residents in the US Gulf Coast. Risk Analysis, 36(11), 2136-2157.

Spence, A., Poortinga, W., \& Pidgeon, N. (2012). The psychological distance of climate change. Risk Analysis, 32(6), 957-972.

Stott, P. (2016). How climate change affects extreme weather events. Science, 352(6293), 15171518. 
Tichenor, P. J., Donohue, G. A., \& Olien, C. N. (1970). Mass media flow and differential growth in knowledge. Public Opinion Quarterly, 34(2), 159-170.

Trenberth, K. E. (2012). Framing the way to relate climate extremes to climate change. Climatic Change, 115(2), 283-290.

Veenstra, A. S., Hossain, M. D., \& Lyons, B. A. (2014). Partisan media and discussion as enhancers of the belief gap. Mass Communication and Society, 17(6), 874-897.

Wadsworth, B. (1984). Piaget's Theory of Cognitive and Affective Development. Longman, New York.

Walsh, B.W. (2014, Jan 06). Climate change might just be driving the historic cold snap. TIME. Retrieved from http://science.time.com/2014/01/06/climate-change-driving-cold-weather. Accessed 02 March 2017.

Waugh, D. W., Sobel, A. H., \& Polvani, L. M. (2017). What is the polar vortex and how does it influence weather? Bulletin of the American Meteorological Society, 98(1), 37-44.

Weber, E. U., \& Stern, P. C. (2011). Public understanding of climate change in the United States. American Psychologist, 66(4), 315.

Wolter, K., Eischeid, J. K., Quan, X. W., Chase, T. N., Hoerling, M., Dole, R. M., ... \& Walsh, J. E. (2015). How Unusual was the Cold Winter of 2013/14 in the Upper Midwest?. Bulletin of the American Meteorological Society, 96(12), S10-S14.

Zaval, L., Keenan, E. A., Johnson, E. J., \& Weber, E. U. (2014). How warm days increase belief in global warming. Nature Climate Change, 4(2), 143-147.

Zhao, X. (2009). Media use and global warming perceptions: A snapshot of the reinforcing spirals. Communication Research, 36(5), 698-723. 
Zhou, J. (2016). Boomerangs versus javelins: How polarization constrains communication on climate change. Environmental Politics, 25(5), 788-811. 
Table 1. Extreme Weather (Self-Reports) and Climate Change Beliefs

\begin{tabular}{|c|c|c|c|c|c|c|c|c|c|c|c|c|}
\hline & \multicolumn{4}{|c|}{...Is Occurring } & \multicolumn{4}{|c|}{...Due to Humans } & \multicolumn{4}{|c|}{ Scientists Agree } \\
\hline & B & S.E. & $\operatorname{Exp}(B)$ & $\mathrm{p}$ & B & S.E. & $\operatorname{Exp}(B)$ & $\mathrm{p}$ & B & S.E. & $\operatorname{Exp}(B)$ & $p$ \\
\hline Age & -0.01 & 0.00 & 0.99 & 0.030 & -0.01 & 0.00 & 0.99 & 0.004 & -0.01 & 0.00 & 0.99 & 0.005 \\
\hline Gender & -0.02 & 0.09 & 0.98 & 0.817 & -0.19 & 0.12 & 0.83 & 0.113 & -0.02 & 0.09 & 0.99 & 0.868 \\
\hline Black & -0.73 & 0.17 & 0.48 & 0.000 & -0.36 & 0.22 & 0.70 & 0.103 & -0.74 & 0.18 & 0.48 & 0.000 \\
\hline Hispanic & 0.11 & 0.18 & 1.12 & 0.518 & 0.52 & 0.25 & 1.69 & 0.034 & 0.39 & 0.19 & 1.48 & 0.038 \\
\hline Education & 0.21 & 0.03 & 1.23 & 0.000 & 0.19 & 0.03 & 1.21 & 0.000 & 0.20 & 0.03 & 1.22 & 0.000 \\
\hline Party & -0.69 & 0.03 & 0.50 & 0.000 & -0.50 & 0.04 & 0.61 & 0.000 & -0.57 & 0.03 & 0.57 & 0.000 \\
\hline Polar Vortex & 0.31 & 0.11 & 1.37 & 0.005 & 0.44 & 0.16 & 1.56 & 0.004 & 0.37 & 0.12 & 1.44 & 0.002 \\
\hline Drought & 0.39 & 0.09 & 1.48 & 0.000 & 0.25 & 0.12 & 1.28 & 0.046 & 0.20 & 0.09 & 1.22 & 0.033 \\
\hline Hurricane & 0.05 & 0.12 & 1.06 & 0.654 & 0.10 & 0.16 & 1.10 & 0.561 & 0.06 & 0.12 & 1.06 & 0.652 \\
\hline Tornado & -0.06 & 0.11 & 0.95 & 0.620 & 0.04 & 0.16 & 1.04 & 0.809 & -0.05 & 0.11 & 0.95 & 0.673 \\
\hline Flood & 0.08 & 0.10 & 1.08 & 0.442 & 0.18 & 0.14 & 1.19 & 0.205 & 0.18 & 0.10 & 1.20 & 0.080 \\
\hline Constant & 1.809 & 0.213 & 6.105 & 0.000 & 1.894 & 0.29 & 6.645 & 0.000 & 2.002 & 0.22 & 7.406 & 0.000 \\
\hline$N$ & 3009 & & & & 1767 & & & & 2939 & & & \\
\hline Nagelkerke R2 & 0.33 & & & & 0.20 & & & & 0.25 & & & \\
\hline
\end{tabular}


Table 2. Polar Vortex, Drought, and Climate Change Beliefs, across Education and Political Orientation

\begin{tabular}{|c|c|c|c|c|c|c|c|c|c|c|c|c|}
\hline & \multicolumn{4}{|c|}{...Is Occurring } & \multicolumn{4}{|c|}{...Due to Humans } & \multicolumn{4}{|c|}{ Scientists Agree } \\
\hline & B & S.E. & $\operatorname{Exp}(B)$ & $\mathrm{p}$ & B & S.E. & $\operatorname{Exp}(B)$ & $p$ & B & S.E. & $\operatorname{Exp}(B)$ & $p$ \\
\hline Age & -0.01 & 0.00 & 0.99 & 0.029 & -0.01 & 0.00 & 0.99 & 0.004 & -0.01 & 0.00 & 0.99 & 0.005 \\
\hline Gender & -0.02 & 0.09 & 0.98 & 0.793 & -0.18 & 0.12 & 0.83 & 0.123 & -0.02 & 0.09 & 0.98 & 0.828 \\
\hline Black & -0.67 & 0.17 & 0.51 & 0.000 & -0.27 & 0.22 & 0.76 & 0.222 & -0.69 & 0.18 & 0.50 & 0.000 \\
\hline Hispanic & 0.09 & 0.18 & 1.09 & 0.608 & 0.54 & 0.25 & 1.71 & 0.029 & 0.37 & 0.19 & 1.44 & 0.050 \\
\hline Education & 0.15 & 0.03 & 1.16 & 0.000 & 0.24 & 0.05 & 1.27 & 0.000 & 0.15 & 0.04 & 1.17 & 0.000 \\
\hline Party & -0.61 & 0.04 & 0.54 & 0.000 & -0.38 & 0.06 & 0.69 & 0.000 & -0.51 & 0.04 & 0.60 & 0.000 \\
\hline Polar Vortex & 0.14 & 0.35 & 1.15 & 0.682 & 1.24 & 0.48 & 3.47 & 0.009 & 0.11 & 0.37 & 1.12 & 0.759 \\
\hline Drought & 0.56 & 0.27 & 1.74 & 0.038 & 0.98 & 0.35 & 2.67 & 0.005 & 0.37 & 0.28 & 1.45 & 0.186 \\
\hline Hurricane & 0.05 & 0.12 & 1.06 & 0.653 & 0.10 & 0.16 & 1.11 & 0.531 & 0.05 & 0.12 & 1.06 & 0.665 \\
\hline Tornado & -0.05 & 0.11 & 0.96 & 0.691 & 0.04 & 0.16 & 1.04 & 0.803 & -0.04 & 0.12 & 0.96 & 0.730 \\
\hline Flood & 0.08 & 0.10 & 1.08 & 0.461 & 0.18 & 0.14 & 1.20 & 0.195 & 0.18 & 0.10 & 1.20 & 0.084 \\
\hline Vortex X Edu & 0.19 & 0.07 & 1.21 & 0.007 & -0.09 & 0.09 & 0.92 & 0.356 & 0.17 & 0.07 & 1.19 & 0.016 \\
\hline Vortex X Party & -0.16 & 0.08 & 0.85 & 0.031 & -0.18 & 0.10 & 0.84 & 0.073 & -0.11 & 0.08 & 0.90 & 0.150 \\
\hline Drought X Edu & 0.06 & 0.05 & 1.07 & 0.228 & -0.07 & 0.07 & 0.93 & 0.327 & 0.04 & 0.05 & 1.04 & 0.433 \\
\hline Drought X Party & -0.12 & 0.06 & 0.89 & 0.049 & -0.19 & 0.08 & 0.83 & 0.018 & -0.09 & 0.06 & 0.91 & 0.120 \\
\hline Constant & 1.76 & 0.24 & 5.81 & 0.000 & 1.43 & 0.33 & 4.16 & 0.000 & 1.96 & 0.25 & 7.12 & 0.000 \\
\hline$N$ & 3009 & & & & 1767 & & & & 2939 & & & \\
\hline Nagelkerke R2 & 0.33 & & & & 0.20 & & & & 0.26 & & & \\
\hline
\end{tabular}


Table 3. Extreme Weather (Objective Indicators) and Climate Beliefs

\begin{tabular}{|c|c|c|c|c|c|c|c|c|c|c|c|c|}
\hline & \multicolumn{4}{|c|}{....Is Occurring } & \multicolumn{4}{|c|}{...Due to Humans } & \multicolumn{4}{|c|}{ Scientists Agree } \\
\hline & B & S.E. & $\operatorname{Exp}(B)$ & $\mathrm{p}$ & B & S.E. & $\operatorname{Exp}(B)$ & $\mathrm{p}$ & B & S.E. & $\operatorname{Exp}(B)$ & $\mathrm{p}$ \\
\hline Age & -0.01 & 0.00 & 0.99 & 0.015 & -0.01 & 0.00 & 0.99 & 0.001 & -0.01 & 0.00 & 0.99 & 0.001 \\
\hline Gender & -0.06 & 0.09 & 0.94 & 0.495 & -0.21 & 0.12 & 0.81 & 0.075 & -0.05 & 0.09 & 0.95 & 0.571 \\
\hline Black & -0.84 & 0.16 & 0.43 & 0.000 & -0.49 & 0.22 & 0.61 & 0.022 & -0.79 & 0.17 & 0.45 & 0.000 \\
\hline Hispanic & 0.10 & 0.17 & 1.10 & 0.577 & 0.50 & 0.25 & 1.65 & 0.042 & 0.31 & 0.19 & 1.37 & 0.091 \\
\hline Education & 0.22 & 0.03 & 1.24 & 0.000 & 0.21 & 0.03 & 1.24 & 0.000 & 0.21 & 0.03 & 1.23 & 0.000 \\
\hline Party & -0.69 & 0.03 & 0.50 & 0.000 & -0.50 & 0.04 & 0.61 & 0.000 & -0.58 & 0.03 & 0.56 & 0.000 \\
\hline Drought OBJ & 0.21 & 0.23 & 1.24 & 0.343 & -0.08 & 0.31 & 0.92 & 0.792 & 0.30 & 0.23 & 1.36 & 0.193 \\
\hline Hurricane OBJ & 0.21 & 0.22 & 1.23 & 0.348 & -0.03 & 0.31 & 0.97 & 0.924 & -0.12 & 0.22 & 0.89 & 0.592 \\
\hline Tornado OBJ & -0.26 & 0.17 & 0.78 & 0.141 & -0.19 & 0.25 & 0.83 & 0.441 & -0.17 & 0.18 & 0.84 & 0.324 \\
\hline Flood OBJ & 0.01 & 0.18 & 1.01 & 0.974 & 0.22 & 0.25 & 1.25 & 0.383 & 0.04 & 0.18 & 1.04 & 0.833 \\
\hline Constant & 2.11 & 0.20 & 8.26 & 0.000 & 2.24 & 0.28 & 9.36 & 0.000 & 2.30 & 0.21 & 9.97 & 0.000 \\
\hline $\mathrm{N}$ & 3020 & & & & 1774 & & & & 2950 & & & \\
\hline Nagelkerke R2 & 0.32 & & & & 0.19 & & & & 0.25 & & & \\
\hline
\end{tabular}


Table 4. Extreme Weather (Objective Indicators and Self-Reports) and Climate Beliefs

\begin{tabular}{|c|c|c|c|c|c|c|c|c|c|c|c|c|}
\hline & \multicolumn{4}{|c|}{...Is Occurring } & \multicolumn{4}{|c|}{...Due to Humans } & \multicolumn{4}{|c|}{ Scientists Agree } \\
\hline & B & S.E. & $\operatorname{Exp}(B)$ & $\mathrm{p}$ & B & S.E. & $\operatorname{Exp}(B)$ & $\mathrm{p}$ & B & S.E. & $\operatorname{Exp}(B)$ & $\mathrm{p}$ \\
\hline Age & -0.01 & 0.00 & 0.99 & 0.034 & -0.01 & 0.00 & 0.99 & 0.004 & -0.01 & 0.00 & 0.99 & 0.006 \\
\hline Gender & -0.02 & 0.09 & 0.98 & 0.834 & -0.19 & 0.12 & 0.83 & 0.117 & -0.01 & 0.09 & 0.99 & 0.890 \\
\hline Black & -0.73 & 0.17 & 0.48 & 0.000 & -0.36 & 0.22 & 0.70 & 0.103 & -0.73 & 0.18 & 0.48 & 0.000 \\
\hline Hispanic & 0.08 & 0.18 & 1.08 & 0.657 & 0.53 & 0.25 & 1.69 & 0.034 & 0.36 & 0.19 & 1.44 & 0.053 \\
\hline Education & 0.20 & 0.03 & 1.22 & 0.000 & 0.19 & 0.04 & 1.21 & 0.000 & 0.20 & 0.03 & 1.22 & 0.000 \\
\hline Party & -0.69 & 0.03 & 0.50 & 0.000 & -0.50 & 0.04 & 0.61 & 0.000 & -0.57 & 0.03 & 0.57 & 0.000 \\
\hline Drought OBJ & 0.19 & 0.23 & 1.22 & 0.394 & -0.04 & 0.32 & 0.96 & 0.889 & 0.31 & 0.24 & 1.37 & 0.182 \\
\hline Hurricane OBJ & 0.25 & 0.23 & 1.29 & 0.268 & -0.07 & 0.32 & 0.93 & 0.826 & -0.12 & 0.23 & 0.89 & 0.597 \\
\hline Tornado OBJ & -0.29 & 0.18 & 0.75 & 0.095 & -0.22 & 0.25 & 0.80 & 0.386 & -0.18 & 0.18 & 0.84 & 0.322 \\
\hline Flood OBJ & 0.02 & 0.18 & 1.02 & 0.900 & 0.25 & 0.26 & 1.28 & 0.334 & 0.02 & 0.18 & 1.02 & 0.912 \\
\hline Tornado Self & -0.03 & 0.11 & 0.98 & 0.822 & 0.04 & 0.16 & 1.04 & 0.826 & -0.03 & 0.12 & 0.97 & 0.823 \\
\hline Hurricane Self & 0.02 & 0.12 & 1.02 & 0.870 & 0.09 & 0.17 & 1.10 & 0.578 & 0.06 & 0.13 & 1.06 & 0.630 \\
\hline Drought Self & 0.40 & 0.09 & 1.49 & 0.000 & 0.26 & 0.13 & 1.30 & 0.037 & 0.19 & 0.09 & 1.21 & 0.045 \\
\hline Polar Vortex Self & 0.31 & 0.11 & 1.37 & 0.005 & 0.44 & 0.16 & 1.55 & 0.005 & 0.37 & 0.12 & 1.45 & 0.001 \\
\hline Flood Self & 0.10 & 0.10 & 1.10 & 0.350 & 0.18 & 0.14 & 1.20 & 0.196 & 0.18 & 0.10 & 1.20 & 0.077 \\
\hline Constant & 1.86 & 0.22 & 6.39 & 0.000 & 1.91 & 0.29 & 6.72 & 0.000 & 2.03 & 0.22 & 7.59 & 0.000 \\
\hline $\mathrm{N}$ & 3009 & & & & 1767 & & & & 2939 & & & \\
\hline Nagelkerke R2 & 0.33 & & & & 0.20 & & & & 0.25 & & & \\
\hline
\end{tabular}


Table 5. Self-reported polar vortex experience within U.S. Census Regions

\begin{tabular}{|c|c|c|c|c|c|c|c|c|c|c|c|}
\hline & & $\mathrm{B}$ & S.E. & $\operatorname{Exp}(B)$ & $p$ & & & B & S.E. & $\operatorname{Exp}(B)$ & $p$ \\
\hline \multirow[t]{11}{*}{ Midwest } & Age & -0.02 & 0.01 & 0.99 & 0.005 & West & Age & -0.02 & 0.01 & 0.98 & 0.031 \\
\hline & Gender & -0.39 & 0.17 & 0.68 & 0.020 & & Gender & -0.26 & 0.36 & 0.77 & 0.478 \\
\hline & Black & -0.50 & 0.36 & 0.61 & 0.161 & & Black & -18.02 & 9622.58 & 0.00 & 0.999 \\
\hline & Hispanic & 0.09 & 0.48 & 1.10 & 0.848 & & Hispanic & -1.54 & 1.04 & 0.22 & 0.138 \\
\hline & Education & 0.31 & 0.05 & 1.37 & 0.000 & & Education & 0.29 & 0.12 & 1.34 & 0.014 \\
\hline & Party & -0.12 & 0.06 & 0.89 & 0.053 & & Party & 0.12 & 0.14 & 1.12 & 0.392 \\
\hline & Liberal News & 0.22 & 0.09 & 1.25 & 0.014 & & Liberal News & 0.35 & 0.15 & 1.42 & 0.017 \\
\hline & Conservative News & -0.02 & 0.10 & 0.98 & 0.826 & & Conservative News & -0.09 & 0.23 & 0.91 & 0.691 \\
\hline & Constant & -0.35 & 0.40 & 0.71 & 0.386 & & Constant & -3.20 & 0.92 & 0.04 & 0.001 \\
\hline & $\mathrm{N}$ & 708 & & & & & N & 771 & & & \\
\hline & Nagelkerke R2 & 0.16 & & & & & Nagelkerke R2 & 0.10 & & & \\
\hline \multirow[t]{11}{*}{ Northeast } & Age & -0.02 & 0.01 & 0.98 & 0.001 & South & Age & -0.02 & 0.01 & 0.98 & 0.000 \\
\hline & Gender & -0.47 & 0.19 & 0.63 & 0.013 & & Gender & -0.19 & 0.18 & 0.83 & 0.296 \\
\hline & Black & -1.01 & 0.41 & 0.36 & 0.013 & & Black & -1.74 & 0.44 & 0.18 & 0.000 \\
\hline & Hispanic & -0.95 & 0.43 & 0.39 & 0.027 & & Hispanic & -2.06 & 0.73 & 0.13 & 0.005 \\
\hline & Education & 0.11 & 0.05 & 1.11 & 0.046 & & Education & 0.22 & 0.05 & 1.24 & 0.000 \\
\hline & Party & -0.02 & 0.07 & 0.98 & 0.792 & & Party & -0.20 & 0.07 & 0.82 & 0.004 \\
\hline & Liberal News & 0.11 & 0.10 & 1.11 & 0.268 & & Liberal News & 0.02 & 0.09 & 1.02 & 0.797 \\
\hline & Conservative News & -0.13 & 0.12 & 0.88 & 0.247 & & Conservative News & 0.15 & 0.10 & 1.16 & 0.143 \\
\hline & Constant & 0.37 & 0.43 & 1.45 & 0.389 & & Constant & -0.36 & 0.42 & 0.70 & 0.393 \\
\hline & $\mathrm{N}$ & 543 & & & & & $\mathrm{~N}$ & 1,003 & & & \\
\hline & Nagelkerke R2 & 0.09 & & & & & Nagelkerke R2 & 0.13 & & & \\
\hline
\end{tabular}


Table 6. Predictors of drought self-reported experience

\begin{tabular}{lccccccccc}
\hline & B & \multicolumn{1}{l}{ S.E. } & Exp(B) & $p$ & B & S.E. & Exp(B) & $p$ \\
\hline Drought OBJ & & & & & & & & \\
Age & 0.90 & 0.19 & 2.47 & 0.000 & 0.89 & 0.19 & 2.44 & 0.000 \\
Gender & 0.01 & 0.00 & 1.01 & 0.000 & 0.01 & 0.00 & 1.01 & 0.000 \\
Black & -0.14 & 0.08 & 0.87 & 0.080 & -0.14 & 0.08 & 0.87 & 0.079 \\
Hispanic & -1.43 & 0.20 & 0.24 & 0.000 & -1.43 & 0.20 & 0.24 & 0.000 \\
Education & 0.49 & 0.15 & 1.63 & 0.001 & 0.49 & 0.15 & 1.63 & 0.001 \\
Party & 0.04 & 0.02 & 1.04 & 0.057 & 0.04 & 0.02 & 1.04 & 0.056 \\
Liberal News & 0.01 & 0.03 & 1.01 & 0.763 & 0.01 & 0.03 & 1.01 & 0.761 \\
Conservative News & 0.14 & 0.04 & 1.15 & 0.000 & 0.14 & 0.04 & 1.15 & 0.000 \\
Drought OBJ X Lib News & -0.04 & 0.04 & 0.96 & 0.406 & 0.01 & 0.09 & 1.01 & 0.889 \\
Constant & & & & & 0.06 & 0.09 & 1.06 & 0.546 \\
\hline N & -0.98 & 0.19 & 0.38 & 0.000 & -0.98 & 0.19 & 0.38 & 0.000 \\
\hline Nagelkerke R2 & 3014 & & & & 3014 & & & \\
\hline
\end{tabular}


Table A1. OLS model for combined warming/anthropogenic belief measure

\begin{tabular}{lcccc}
\hline & B & S.E. & Beta & p \\
\hline (Constant) & 3.81 & 0.10 & & .000 \\
Age & 0.00 & 0.00 & -0.04 & 0.016 \\
Gender & 0.00 & 0.03 & 0.00 & 0.904 \\
Black & -0.04 & 0.07 & -0.01 & 0.552 \\
Hispanic & 0.19 & 0.07 & 0.04 & 0.007 \\
Education & 0.03 & 0.01 & 0.04 & 0.086 \\
Party & -0.28 & 0.02 & -0.40 & .000 \\
Flood & -0.01 & 0.04 & 0.00 & 0.823 \\
Hurricane & 0.07 & 0.05 & 0.03 & 0.107 \\
Tornado & -0.03 & 0.04 & -0.01 & 0.466 \\
Polar Vortex & -0.28 & 0.14 & -0.11 & 0.048 \\
Liberal News & 0.19 & 0.03 & 0.17 & .000 \\
Conservative News & -0.31 & 0.03 & -0.28 & .000 \\
Edu X Vortex & 0.06 & 0.03 & 0.10 & 0.015 \\
Party X Vortex & 0.04 & 0.03 & 0.05 & 0.186 \\
Drought & -0.08 & 0.04 & -0.04 & 0.048 \\
Edu X Drought & -0.06 & 0.05 & -0.03 & 0.178 \\
Party X Drought & 0.04 & 0.11 & 0.02 & 0.718 \\
Lib News X Drought & 0.01 & 0.02 & 0.03 & 0.476 \\
Con News X Drought & 0.01 & 0.03 & 0.01 & 0.733 \\
Lib News X Vortex & 0.04 & -0.01 & 0.519 \\
Con News X Vortex & 0.04 & 0.00 & 0.906 \\
N & & & & 2411 \\
R2 & 0.02 & & 0.47 \\
\hline
\end{tabular}


Table A2. Education and political orientation interactions for all weather event categories

\begin{tabular}{|c|c|c|c|c|c|c|c|c|c|c|c|c|}
\hline & $\mathrm{B}$ & S.E. & $\operatorname{Exp}(B)$ & $p$ & B & S.E. & $\operatorname{Exp}(B)$ & $p$ & B & S.E. & $\operatorname{Exp}(B)$ & $\mathrm{p}$ \\
\hline Age & -0.01 & 0.00 & 0.99 & 0.028 & -0.01 & 0.00 & 0.99 & 0.002 & -0.01 & 0.00 & 0.99 & 0.005 \\
\hline Gender & -0.03 & 0.09 & 0.97 & 0.758 & -0.20 & 0.12 & 0.82 & 0.103 & -0.03 & 0.09 & 0.97 & 0.767 \\
\hline Black & -0.68 & 0.17 & 0.51 & 0.000 & -0.25 & 0.22 & 0.78 & 0.257 & -0.69 & 0.18 & 0.50 & 0.000 \\
\hline Hispanic & 0.08 & 0.18 & 1.08 & 0.661 & 0.54 & 0.25 & 1.72 & 0.029 & 0.36 & 0.19 & 1.43 & 0.056 \\
\hline Education & 0.14 & 0.04 & 1.15 & 0.001 & 0.19 & 0.06 & 1.21 & 0.001 & 0.15 & 0.04 & 1.16 & 0.000 \\
\hline Party & -0.61 & 0.05 & 0.54 & 0.000 & -0.46 & 0.07 & 0.63 & 0.000 & -0.54 & 0.05 & 0.58 & 0.000 \\
\hline Polar Vortex & 0.16 & 0.35 & 1.17 & 0.652 & 1.30 & 0.48 & 3.66 & 0.007 & 0.14 & 0.37 & 1.15 & 0.700 \\
\hline Drought & 0.53 & 0.27 & 1.70 & 0.049 & 0.94 & 0.35 & 2.55 & 0.008 & 0.35 & 0.28 & 1.42 & 0.216 \\
\hline Flood & 0.38 & 0.29 & 1.46 & 0.195 & -0.44 & 0.39 & 0.65 & 0.260 & 0.25 & 0.31 & 1.28 & 0.425 \\
\hline Hurricane & -0.36 & 0.33 & 0.70 & 0.268 & -0.66 & 0.44 & 0.52 & 0.134 & -0.25 & 0.35 & 0.78 & 0.466 \\
\hline Tornado & -0.21 & 0.32 & 0.81 & 0.522 & -0.20 & 0.44 & 0.82 & 0.651 & -0.36 & 0.34 & 0.70 & 0.291 \\
\hline Edu X Vortex & 0.19 & 0.07 & 1.20 & 0.008 & -0.09 & 0.09 & 0.91 & 0.325 & 0.18 & 0.07 & 1.19 & 0.016 \\
\hline Edu X Drought & 0.07 & 0.05 & 1.07 & 0.189 & -0.06 & 0.07 & 0.95 & 0.420 & 0.05 & 0.05 & 1.05 & 0.367 \\
\hline Edu X Flood & -0.07 & 0.06 & 0.93 & 0.221 & 0.10 & 0.08 & 1.10 & 0.219 & -0.07 & 0.06 & 0.94 & 0.276 \\
\hline Edu X Hurricane & 0.08 & 0.07 & 1.09 & 0.236 & 0.15 & 0.10 & 1.16 & 0.124 & 0.08 & 0.07 & 1.08 & 0.282 \\
\hline Edu X Tornado & 0.07 & 0.07 & 1.07 & 0.325 & -0.05 & 0.09 & 0.95 & 0.552 & 0.03 & 0.07 & 1.03 & 0.693 \\
\hline Party $X$ Hurricane & 0.04 & 0.08 & 1.04 & 0.574 & 0.10 & 0.11 & 1.10 & 0.379 & 0.01 & 0.08 & 1.02 & 0.853 \\
\hline Party X Tornado & -0.02 & 0.07 & 0.98 & 0.809 & 0.16 & 0.10 & 1.18 & 0.114 & 0.07 & 0.07 & 1.07 & 0.342 \\
\hline Party X Flood & -0.02 & 0.07 & 0.98 & 0.779 & 0.11 & 0.09 & 1.12 & 0.240 & 0.05 & 0.07 & 1.05 & 0.473 \\
\hline Party X Vortex & -0.17 & 0.08 & 0.85 & 0.029 & -0.19 & 0.10 & 0.83 & 0.061 & -0.12 & 0.08 & 0.89 & 0.123 \\
\hline Party X Drought & -0.11 & 0.06 & 0.89 & 0.059 & -0.19 & 0.08 & 0.83 & 0.018 & -0.10 & 0.06 & 0.91 & 0.118 \\
\hline Constant & 1.80 & 0.26 & 6.04 & 0.000 & 1.83 & 0.36 & 6.26 & 0.000 & 2.07 & 0.27 & 7.96 & 0.000 \\
\hline N & & & & 3009 & & & & 1767 & & & & 2939 \\
\hline Nagelkerke $R^{2}$ & & & & 0.33 & & & & 0.21 & & & & 0.26 \\
\hline
\end{tabular}


Table A3. Polar Vortex, Drought, and Climate Change Beliefs, across Education, Political Orientation, and Media Use

\begin{tabular}{|c|c|c|c|c|c|c|c|c|c|c|c|c|}
\hline & $\mathrm{B}$ & S.E. & $\operatorname{Exp}(B)$ & $p$ & $\mathrm{~B}$ & S.E. & $\operatorname{Exp}(B)$ & $\mathrm{p}$ & $\mathrm{B}$ & S.E. & $\operatorname{Exp}(B)$ & $p$ \\
\hline Age & 0.00 & 0.00 & 1.00 & 0.450 & -0.01 & 0.00 & 0.99 & 0.046 & 0.00 & 0.00 & 1.00 & 0.874 \\
\hline Gender & -0.09 & 0.09 & 0.92 & 0.349 & -0.16 & 0.12 & 0.85 & 0.195 & -0.12 & 0.09 & 0.89 & 0.210 \\
\hline Black & -0.65 & 0.17 & 0.52 & 0.000 & -0.20 & 0.23 & 0.82 & 0.375 & -0.66 & 0.18 & 0.52 & 0.000 \\
\hline Hispanic & 0.14 & 0.18 & 1.15 & 0.420 & 0.57 & 0.25 & 1.77 & 0.023 & 0.43 & 0.19 & 1.54 & 0.024 \\
\hline Education & 0.11 & 0.04 & 1.12 & 0.002 & 0.18 & 0.05 & 1.20 & 0.000 & 0.13 & 0.04 & 1.13 & 0.001 \\
\hline Party & -0.46 & 0.04 & 0.63 & 0.000 & -0.24 & 0.06 & 0.79 & 0.000 & -0.36 & 0.05 & 0.70 & 0.000 \\
\hline Polar Vortex & -0.42 & 0.38 & 0.66 & 0.270 & 0.90 & 0.51 & 2.46 & 0.077 & -0.25 & 0.39 & 0.78 & 0.534 \\
\hline Drought & 0.26 & 0.28 & 1.30 & 0.355 & 0.83 & 0.36 & 2.30 & 0.022 & 0.08 & 0.29 & 1.08 & 0.787 \\
\hline Hurricane & 0.10 & 0.13 & 1.11 & 0.409 & 0.14 & 0.17 & 1.15 & 0.422 & 0.11 & 0.13 & 1.12 & 0.383 \\
\hline Tornado & -0.02 & 0.12 & 0.98 & 0.873 & 0.12 & 0.17 & 1.13 & 0.461 & 0.00 & 0.12 & 1.00 & 0.980 \\
\hline Flood & 0.07 & 0.11 & 1.07 & 0.505 & 0.20 & 0.15 & 1.22 & 0.175 & 0.19 & 0.11 & 1.21 & 0.084 \\
\hline Liberal News & 0.59 & 0.08 & 1.80 & 0.000 & 0.35 & 0.10 & 1.42 & 0.000 & 0.45 & 0.09 & 1.57 & 0.000 \\
\hline Conservative News & -0.50 & 0.08 & 0.61 & 0.000 & -0.59 & 0.12 & 0.55 & 0.000 & -0.54 & 0.07 & 0.59 & 0.000 \\
\hline Edu X Vortex & 0.19 & 0.08 & 1.21 & 0.011 & -0.05 & 0.10 & 0.96 & 0.630 & 0.18 & 0.08 & 1.19 & 0.019 \\
\hline Party X Vortex & -0.01 & 0.09 & 0.99 & 0.865 & -0.16 & 0.11 & 0.85 & 0.146 & 0.00 & 0.09 & 1.00 & 0.988 \\
\hline Edu X Drought & 0.07 & 0.06 & 1.08 & 0.180 & -0.05 & 0.07 & 0.96 & 0.534 & 0.05 & 0.06 & 1.05 & 0.371 \\
\hline Party X Drought & -0.04 & 0.07 & 0.96 & 0.513 & -0.18 & 0.09 & 0.84 & 0.043 & -0.02 & 0.07 & 0.98 & 0.763 \\
\hline Lib News X Drought & 0.04 & 0.13 & 1.04 & 0.760 & 0.13 & 0.14 & 1.14 & 0.357 & 0.04 & 0.13 & 1.04 & 0.741 \\
\hline Con News X Drought & -0.12 & 0.11 & 0.89 & 0.304 & 0.08 & 0.18 & 1.08 & 0.654 & -0.09 & 0.10 & 0.92 & 0.393 \\
\hline Lib News X Vortex & 0.01 & 0.16 & 1.01 & 0.950 & -0.03 & 0.17 & 0.97 & 0.840 & 0.17 & 0.17 & 1.19 & 0.322 \\
\hline Con News X Vortex & -0.39 & 0.15 & 0.68 & 0.009 & -0.02 & 0.23 & 0.98 & 0.942 & -0.02 & 0.13 & 0.98 & 0.871 \\
\hline Constant & 1.16 & 0.25 & 3.19 & 0.000 & 0.98 & 0.35 & 2.66 & 0.005 & 1.34 & 0.26 & 3.82 & 0.000 \\
\hline
\end{tabular}

N

Nagelkerke $R^{2}$ 
Table A4. Extreme Weather (Objective Indicators Time Splits) and Climate Beliefs

\begin{tabular}{lcccccccccccc}
\hline & B & S.E. & Exp(B) & $p$ & B & S.E. & Exp(B) & $p$ & B & S.E. & Exp(B) & $p$ \\
\hline Age & -0.01 & 0.00 & 0.99 & 0.013 & -0.01 & 0.00 & 0.99 & 0.001 & -0.01 & 0.00 & 0.99 & 0.001 \\
Gender & -0.06 & 0.09 & 0.94 & 0.457 & -0.22 & 0.12 & 0.81 & 0.069 & -0.05 & 0.09 & 0.95 & 0.539 \\
Black & -0.86 & 0.16 & 0.43 & 0.000 & -0.50 & 0.22 & 0.61 & 0.021 & -0.80 & 0.17 & 0.45 & 0.000 \\
Hispanic & 0.08 & 0.18 & 1.09 & 0.637 & 0.46 & 0.25 & 1.59 & 0.059 & 0.31 & 0.19 & 1.37 & 0.095 \\
Education & 0.22 & 0.03 & 1.24 & 0.000 & 0.21 & 0.03 & 1.24 & 0.000 & 0.21 & 0.03 & 1.23 & 0.000 \\
Party & -0.69 & 0.03 & 0.50 & 0.000 & -0.50 & 0.04 & 0.61 & 0.000 & -0.58 & 0.03 & 0.56 & 0.000 \\
Drought OBJ_T1 & 0.00 & 0.00 & 1.00 & 0.713 & 0.00 & 0.00 & 1.00 & 0.245 & 0.00 & 0.00 & 1.00 & 0.299 \\
Hurricane OBJ_T1 & -0.03 & 0.27 & 0.97 & 0.908 & 0.46 & 0.43 & 1.58 & 0.290 & -0.18 & 0.27 & 0.84 & 0.513 \\
Tornado OBJ_T1 & 0.08 & 0.17 & 1.08 & 0.633 & 0.04 & 0.24 & 1.04 & 0.866 & 0.05 & 0.17 & 1.05 & 0.787 \\
Flood OBJ_T1 & 0.00 & 0.00 & 1.00 & 0.812 & 0.00 & 0.00 & 1.00 & 0.110 & 0.00 & 0.00 & 1.00 & 0.331 \\
Hurricane OBJ_T2 & 0.73 & 0.37 & 2.08 & 0.046 & -0.44 & 0.50 & 0.64 & 0.371 & 0.29 & 0.36 & 1.34 & 0.420 \\
Tornado OBJ_T2 & 0.02 & 0.16 & 1.02 & 0.900 & 0.09 & 0.23 & 1.09 & 0.715 & -0.09 & 0.16 & 0.92 & 0.590 \\
Flood OBJ_T2 & -0.28 & 0.17 & 0.75 & 0.092 & -0.10 & 0.24 & 0.91 & 0.695 & -0.15 & 0.17 & 0.87 & 0.395 \\
Constant & 2.25 & 0.22 & 9.52 & 0.000 & 2.37 & 0.30 & 10.73 & 0.000 & 2.32 & 0.23 & 10.15 & 0.000 \\
\hline N & & & & 3020 & & & & 1774 & & & 2950 \\
Nagelkerke R2 & & & & 0.32 & & & & 0.19 & & 0.25 \\
\hline
\end{tabular}


Table A5. Polar vortex self-report, by demographics, partisanship, and region

\begin{tabular}{lrrrr}
\hline & \multicolumn{1}{c}{ B } & \multicolumn{1}{l}{ S.E. } & Exp(B) & \multicolumn{1}{c}{$\mathrm{p}$} \\
\hline Age & -0.02 & 0.003 & 0.98 & .000 \\
Gender & -0.361 & 0.099 & 0.697 & .000 \\
Black & -1.039 & 0.22 & 0.354 & .000 \\
Hispanic & -0.898 & 0.257 & 0.407 & .000 \\
Education & 0.221 & 0.029 & 1.248 & .000 \\
Party & -0.097 & 0.037 & 0.907 & 0.008 \\
Liberal News & 0.137 & 0.049 & 1.147 & 0.005 \\
Conservative News & -0.002 & 0.058 & 0.998 & 0.975 \\
Northeast & 2.6 & 0.199 & 13.469 & .000 \\
Midwest & 2.613 & 0.195 & 13.64 & .000 \\
South & 1.522 & 0.197 & 4.581 & .000 \\
Constant & -2.409 & 0.287 & 0.09 & .000 \\
\hline N & & & & 3025 \\
Nagelkerke $R^{2}$ & & & & 0.25 \\
\hline
\end{tabular}

